
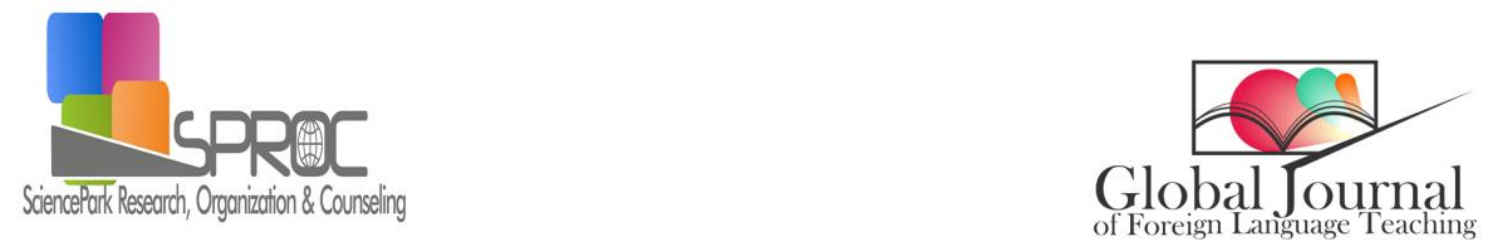

http://sproc.org/ojs/index.php/GJFLT

\title{
The effect of social class on Persian EFL learners' pragmatic performance of Speech act of compliment responses
}

Saman Ebadi *,

Farkhondeh Pursiah,

Suggested Citation:

Global Journal of Foreign Language Teaching 5

Abstract

Saman Ebadi,

E-mail address 
Global Journal of Foreign Language Teaching 5

1. Introduction 
Global Journal of Foreign Language Teaching 5

\section{Method}

2.1. Research design

\subsection{Participants}


Global Journal of Foreign Language Teaching 5

2.3. Instrumentation

2.3. Data Collection Procedure

3. Data Analysis

3.1. Coding Scheme 
Global Journal of Foreign Language Teaching 5 
Global Journal of Foreign Language Teaching 5

4. Results and Discussion 
Global Journal of Foreign Language Teaching 5

66

52

15.5

90.1

21

99

70

79

Total

348

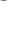


5. Conclusion, implications and suggestions for further research

Reference

The Handbook of Language Variation and Change 
American Speech, 61

sketch.

Language in Society, 19,

Anthropological

Linguistics, 28,

egy Journal of Pragmatics, 12,

Journal of Pragmatics, 41

Second Language Research, 8

132.

, pp.115-

, 22

19

Speech acts and second-language learnin

$e$

Sociolinguistics and Language Acquisition (pp.82-95).

Arizona Working Papers in SLA \& Teaching, 17, 


\section{Appendix 1}

Herber's Compliment Responses Framework $(1986,1989)$

\section{A: Agreement}

\section{I.Acceptances}

Appreciation Token Thanks/Thank you/(smile)

Comment Acceptance Thanks, it's my favorite, too

Praise Upgrade Really brings out the blue in my eyes, doesn t it?

II.Comment History I bought it for the trip to Arizona

III. Transfers

Shift credit/Reassignment My brother gave it to me

Return So s yours

B. Non-agreement

I. Scale Down It s really quite old

II. Questioning Do you really think so?)

III.Nonacceptances

Disagreement (I hate it)

Qualification It's all right, but Len's nicer.)

IV. No acknowledgement (silence)

Appreciation Token

\section{Comment Acceptance}

) Praise Upgrade

Comment History

\section{Reassignment}

Return 
Scale Down

Questioning

Disagreement

Qualification

No Response/No Acknowledgement

\section{Appendix 2}

Personal information

Situation 1 (hair style)

Situation 2 (smart clothing)

Situation 3 (beautiful eyes) 
Situation 4(interior Design)

Situation 5(food Decoration Design)

Situation 6 (Interpersonal skill)

Situation 7 (personality)

Situtation 8 (Hijab)

Situation 9 (Brand new cell phone)

Situation 10 (MP3 Player) 
Situation 11 (Computer ability)

Situation 12 (Sports)

Situation 13 (English ability)

Situation 14 (music)

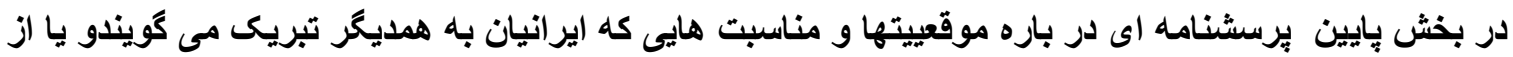

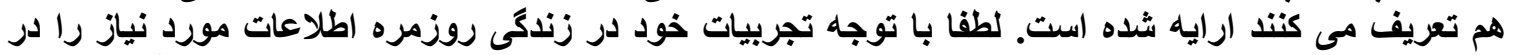

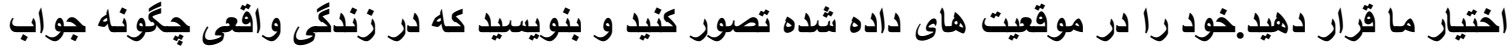

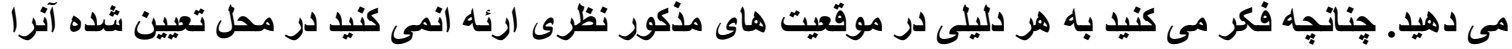

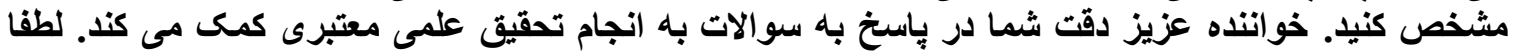

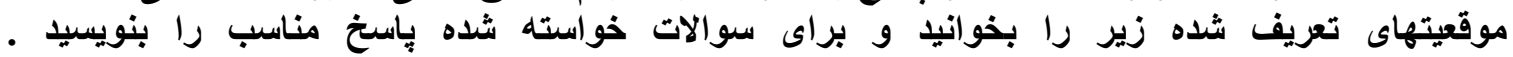

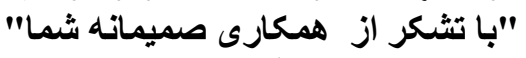

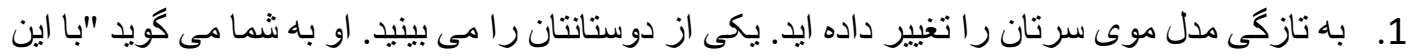

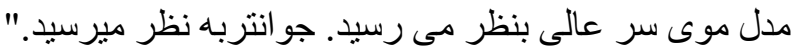

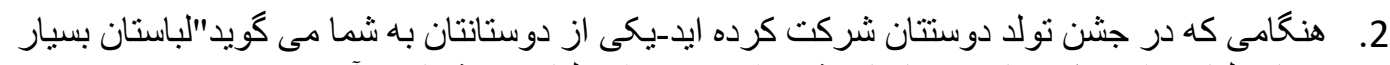

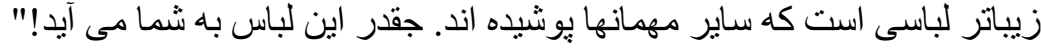

$$
\text { 3. يكى از دوستانتان به شما مى گويد"جشمانتان بسيار جذاب هستند." }
$$

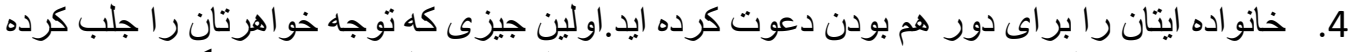

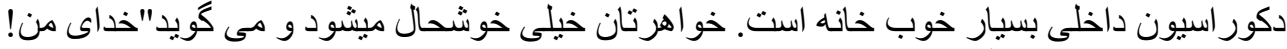

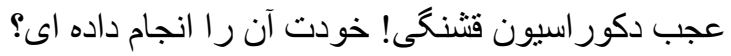




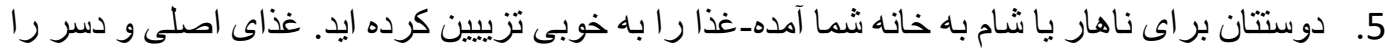

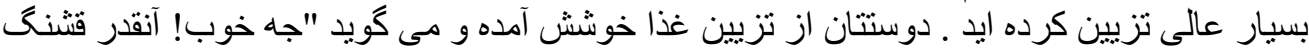
است كه دلم نمى آيد آنر البخور ايد، دوم.

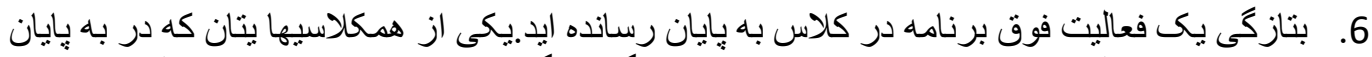

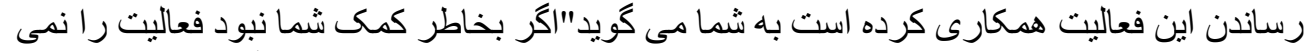

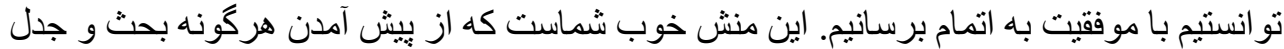

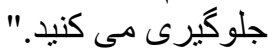

7. شما آدم بسيار آر امى هستيد بكونه اى كه بندرت عصبانى ميشويد. دوستانتان مكررا" به اين خاطر از شما تعريف مى كنتد.

8. در خانو اده به كرات به دليل حجاب و يوششتان از شما تعريف مى شئ دود.

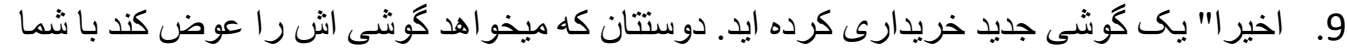

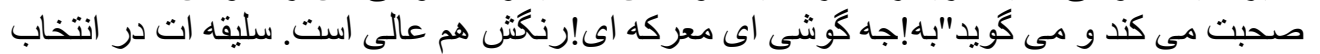

$$
\text { كوشى حرف ندارد." }
$$

10. جديدا" يك ريده ايد. وقت ناهار آن را بيرون مى آوريد تا به موسيقى كوش كنبد-همكلاسيتان

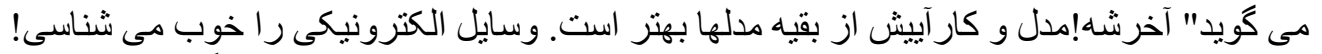

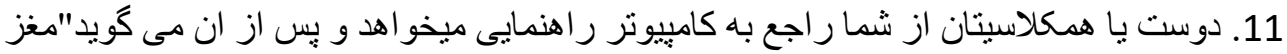

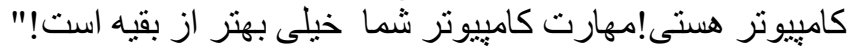

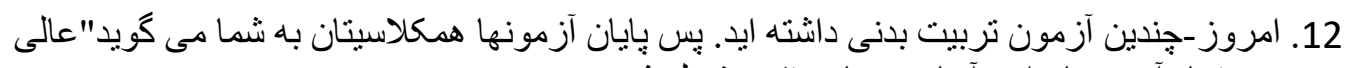

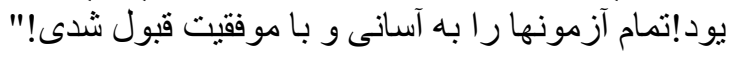

13. بِساز كلاس زبان انكليسى معلم به شما مى كويد"اين روز ها خيلى بيشرفت كرده ایى و تكاليفت را به به

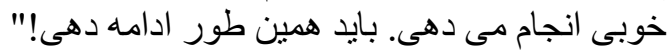

14. در خانه مشغول نو اختن بيانو هستيد. عمويت به بيانو نو اختن شما كوش فر ا مى دهد و آن را تحسين 